\title{
PASSADOS 50 ANOS...
}

MARLY RODRIGUES MEMÓRIAS ASSESSORIA E PROJETOS, SÃO PAULO, SÃO PAULO, BRASIL

Doutora em História pela Universidade Estadual de Campinas (Unicamp), cursou Architectural Conservation, como especialização, no ICCROM-Unesco. Trabalhou nos órgãos públicos de proteção ao patrimônio cultural que atuam em São Paulo. Atualmente dirige Memórias Assessoria e Projetos, escritório voltado a ações relacionadas ao Patrimônio Cultural, História e Memória, sediado na cidade de São Paulo, Brasil. E-mail: marly@mem.com.br

DOI

http://dx.doi.org/10.11606/issn.1980-4466.v13i26espp20-44 


\section{PASSADOS 50 ANOS...}

MARLY RODRIGUES

\section{RESUMO}

O cinquentenário de criação do Conselho de Defesa do Patrimônio Histórico, Arqueológico, Artístico e Turístico de São Paulo (Condephaat) é tomado, neste texto, como uma oportunidade de reflexão sobre o sentido, até o presente, atribuído à proteção de bens culturais pelo poder público. Busca-se focalizar fatores, por exemplo, a influência de concepções herdadas, como as de nacionalismo, ou conceitos que dificultam a renovação das atuais formas de atuação e tendem a distanciar o órgão das expectativas da sociedade contemporânea em relação à construção da memória e à melhoria da qualidade de vida.

\section{PALAVRAS-CHAVE}

Patrimônio cultural. Memória social. Preservação do patrimônio. Políticas públicas. 


\section{AFTER 50 YEARS...}

MARLY RODRIGUES

\section{ABSTRACT}

The fiftieth anniversary of the creation of the Conselho de Defesa do Patrimônio Histórico, Arqueológico, Artístico e Turístico de São Paulo (Condephaat) is taken as an opportunity to reflect on the meaning attributed to the protection of cultural assets by the public power. It seeks to focus factors, for example, the influence of inherited conceptions, such as those of nationalism, or concepts that hinder the renewal of current forms of action and tend to distance the organ from the expectations of contemporary society in relation to the construction of memory and quality of life.

\section{KEYWORDS}

Cultural heritage. Social memory. Heritage preservation. Public policies. 


\section{INTRODUÇÃO}

O cinquentenário de criação do Conselho de Defesa do Patrimônio Histórico, Arqueológico, Artístico e Turístico de São Paulo (Condephaat) parece-nos uma ocasião única para refletirmos sobre o contexto de sua criação e sobre algumas condicionantes que ainda hoje são barreiras para que a ação de tutelar bens culturais se torne uma forma de, como aponta Meneses (2018, p. 1), ao citar Paul Connerton, minimizar a "amnésia estrutural" que deriva da hierarquia de classes.

\section{ERA UM TEMPO...}

A criação das estruturas de tutela do patrimônio cultural federal e paulista coincide com diferentes fases do nacionalismo brasileiro e a elas está relacionada. Na tentativa de compreender a trajetória do Condephaat, criado em 1968, teceremos breves considerações sobre fatores que, anteriores à sua criação, persistem, de forma sutil, nas formas de pensar a instituição do patrimônio e, em consequência, dificultando a aproximação de alguns setores da sociedade do direito à memória. Hobsbawm (1990, p. 126-7), em seus escritos sobre nacionalismo, ressalta que na Europa, entre 1880 e 1914, esse fenômeno contou com a participação de "letrados" que valorizavam a "tradição popular" como "tradição nacional". 
Embora seja conhecido o fato de as tradições poderem ser inventadas ou, no mínimo, escolhidas para representar parte da memória de toda uma nação, diante da diversidade cultural do Brasil, quais seriam as feições do nacional traçadas pelos intelectuais?

Desde 1860, quando os ideais republicanos colocaram o progresso como meta a ser alcançada por meio da modernização do país, intelectuais como Sílvio Romero, Joaquim Nabuco e André Rebouças começaram a traçar o perfil de uma nova nação. A esse respeito, Santos observa ter sido essa a primeira geração de intelectuais "a abordar, a partir de uma multiplicidade de pontos de vista, o fenômeno da diversidade étnica do país" (SANTOS, 2004, p. 1):

Recuperando noções do romantismo alemão, mas, principalmente, absorvendo o ideário vigente do determinismo, implementaram uma nova visão do nacionalismo, no qual a nação passava a ser fundada nos conceitos de terra, raça, língua, folclore, arte e história.

Diante de toda a nação, a consciência da dicotomia entre os Brasis "civilizado", do litoral, e o "outro", do sertão, foi ampliada, por exemplo, quando da divulgação dos escritos de Euclides da Cunha sobre Canudos (1896-1897), e impôs aos intelectuais e políticos liberais e republicanos a superação da indolência e do analfabetismo que caracterizavam as classes populares e dificultavam o almejado progresso nacional. Entre eles estava Alberto Torres, que em 1914 publicou O problema nacional brasileiro, onde fazia propostas para o "reerguimento do caráter nacional" que se somaram a outras propaladas por diversos movimentos - como a Liga Nacionalista, criada por estudantes de Direito do Largo São Francisco - estas veiculadas pela Revista do Brasil, dirigida por Monteiro Lobato (RODRIGUES, 1997, p. 21-7).

No contexto nacionalista da década de 1910, que se prolongaria na seguinte, também foram propostos inúmeros projetos de "obras de melhoramentos e embelezamento" que implicaram a perda de paisagens urbanas tradicionais nas principais cidades brasileiras, o que motivou propostas pioneiras de proteção pública de seus "edifícios mais nobres".

1. Entre outras, as de Wanderley Pinho, apresentadas em 1917 e na década de 1930; de Luís Cedro, em 1923; de Augusto de Lima, deputado mineiro, em 1924; de Jair Lins, em 1925. 
Nascidas de membros das elites culturais e políticas em grande parte congregadas em torno dos institutos históricos e geográficos locais, elas expressavam a "conservação da tradição", o que se opunha à trilha de progresso como algo obrigatório e, também, ao "precipício do cosmopolitismo"2.

Wanderley Pinho, deputado empenhado em instalar a tutela pública sobre bens culturais, preocupava-se com o progresso, mais tarde denominado "rastaquera" por Mário de Andrade que, em nome do futuro, destruía e apagava memórias e negava o passado rural e escravista que criara o "outro" Brasil e estava representado na figura indolente do Jeca Tatu, tornada pública por seu criador, Monteiro Lobato, em 1914.

Pouco depois, sua figura se popularizaria nos meios urbanos como representação do homem do campo, o que talvez não significasse identificação, mas uma referência comparativa que realçava o progresso manifesto nas formas de vida urbana, embora concentrada nas capitais do Sudeste. Na cidade de São Paulo, núcleo e reflexo da acumulação do capital gerado na lavoura de exportação, a mudança se expressava pela acelerada industrialização, pela extensão contínua da cidade e dos problemas de higiene e saneamento e pela maciça presença de figuras sociais até então pouco comuns, os trabalhadores fabris - em grande número, imigrantes. Por muitos, "os estrangeiros" eram vistos como ameaça à nação uma vez que, apoiados em teorias de igualdade social eles reivindicavam direitos e causavam conflitos até então desconhecidos; e continuavam a falar suas línguas e a transmiti-las a seus filhos nas escolas que mantinham, incluídas as que adotavam propostas educacionais libertárias, que integravam ensino a práticas culturais populares.

Fraco, sem força de vontade e desprovido de senso estético, a figura de Jeca Tatu não se enquadrava no ideal de nacionalidade das elites, moldado pelo padrão francês de cultura, que Lobato via como homogeneizador e contra o qual propunha uma "individualidade nacional", sem imitações (AZEVEDO, 2012, p. 27). Antes de Lobato, Almeida Júnior (1850-1899) fez do caipira uma representação do paulista. Então na província cuja produção

2. Expressões de Wanderley Pinho (1918, apud PERES, 1974, p. 97). 
Almeida Junior. Caipira picando fumo (óleo sobre tela, 1899). Acervo Pinacoteca do Estado de São Paulo. In: ENCICLOPÉDIA Itaú Cultural de Arte e Cultura Brasileiras.

São Paulo: Itaú Cultural, 2018.

Disponível em: http:// enciclopedia.itaucultural.org.br/obra14057/ caipira-picando-fumo Acesso em: $21 \mathrm{de} \mathrm{dez}$ 2018.

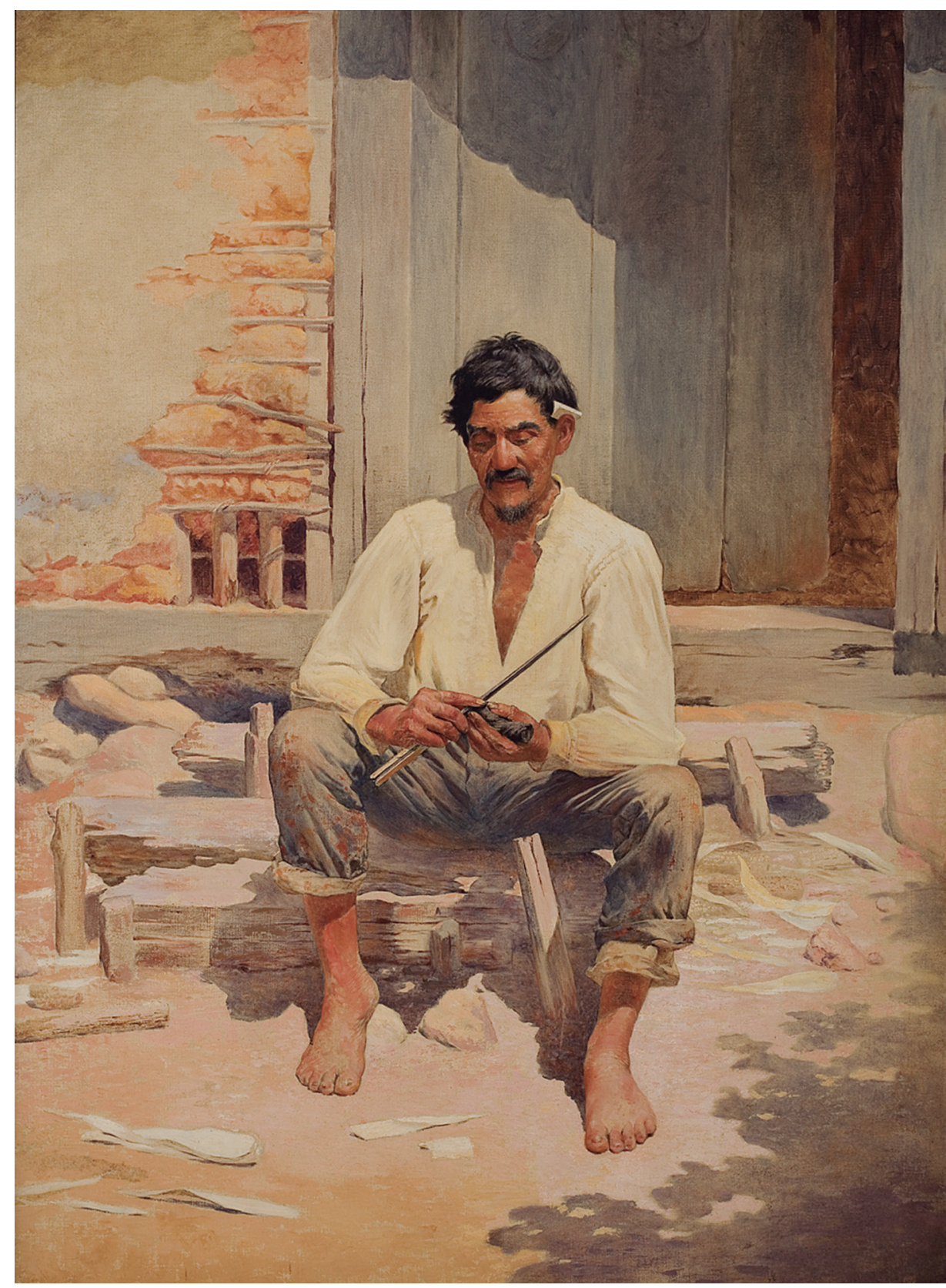

agrícola de exportação sustentava a economia nacional, líderes do Partido Republicano Paulista (PRP) defendiam o federalismo e viam no mameluco e no caipira a representação ideal da identidade paulista (SANTOS, 2004, p. 5) ${ }^{3}$.

3. Almeida Júnior, Caipiras negaceando (1888); Caipira picando fumo (1893); O violeiro (1899). 


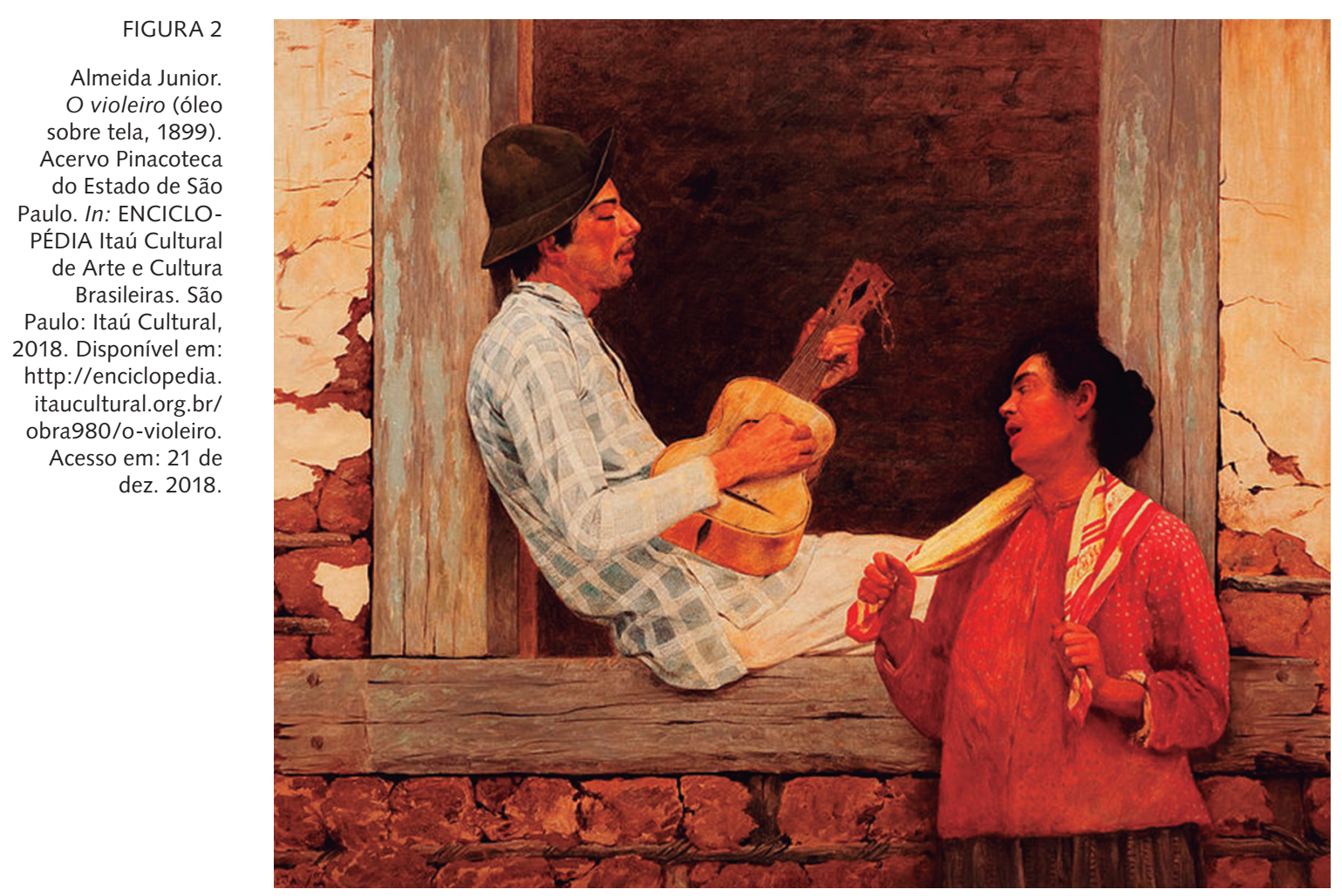

A partir de 1894, quando criado o Instituto Histórico e Geográfico de São Paulo e iniciadas pesquisas de história regional, especialmente do bandeirismo, essas imagens começaram gradativamente a ser substituídas por outra, mitificada, do bandeirante. O mameluco, síntese do branco e do índio, pleno de coragem e discernimento, passaria a representar o "espírito paulista" que justificaria simbolicamente as pretensões políticas de os republicanos de São Paulo conduzirem a nação, de modo a promover seu progresso ${ }^{4}$. Essa representação, contudo, era apenas paulista. O perfil brasileiro foi sintetizado na década de 1920, por Mário de Andrade, na figura de Macunaíma, que, como Jeca Tatu, era preguiçoso, mas, ao contrário deste, representava a mestiçagem, que o autor considerava o núcleo da brasilidade, da identidade de nosso povo (AZEVEDO, 2012, p. 70).

4. Almeida Júnior foi um dos autores destacados da pintura histórica brasileira. Ao seu lado, além de outros, estão Pedro Américo, Vitor Meirelles e Benedito Calixto. 
Tal percepção, de certo, tinha raízes nas pesquisas etnográficas de Mário de Andrade que também orientaram a proposta de anteprojeto do Serviço do Patrimônio Artístico Nacional (Span) por ele elaborado em 1936, a pedido do governo Vargas. Nesse documento, ele ressaltou as obras de arte, puras ou aplicadas, eruditas e populares, como parte do patrimônio nacional. A categoria incluía objetos, monumentos, paisagens e a "arte histórica" (ANDRADE, 1980, p. 90-106); não se tratava, portanto, de realçar a história da nação, mas as representações artísticas que incluíam o passado no imaginário social.

As manifestações da cultura popular e a arte histórica não foram consideradas na elaboração da lei que regeria as ações públicas de tutela do patrimônio cultural brasileiro. A criação do Serviço, ${ }^{5}$ no anteprojeto imaginado por Mário de Andrade como do Patrimônio Artístico Nacional, tornou-se do Patrimônio Histórico e Artístico Nacional (Sphan). Essa definição não incluía aqueles considerados pelos produtores do conhecimento histórico da época, como "fora da história”: negros, índios e brancos pobres. Macunaíma seria posto de lado; perdeu-se a diversidade nele representada e a proteção ao patrimônio nacional nasceria excludente, uma vez que, simbolicamente, passaria a representar "uma certa história", um "certo nacionalismo", e apenas a produção cultural de segmentos sociais cultos e influentes. Perdeu-se, também, o movimento e a diferença, enfim, a historicidade da sociedade, uma vez que a proteção aos bens culturais tomou como tempos históricos referenciais da nacionalidade, a chegada do português, "momento fundador", o século XVIII e nele destacando a arte barroca. Tais referências levariam o próprio Mario de Andrade, em seu primeiro relatório como assistente técnico do Sphan, a afirmar não ser "possível esperar-se de S. Paulo grande coisa com valor artístico tradicional” e lançasse mão de argumentos históricos para justificar essa condição ${ }^{6}$.

Antes mesmo da constituição do Sphan, Vargas, por meio de um decreto, tornara Ouro Preto monumento nacional'. Juntamente com

\footnotetext{
5. Lei n. 378, de 13-1-1937, dá nova organização ao Ministério da Educação e Saúde Pública e no art.46 cria o Serviço de Patrimônio Histórico e Artístico Nacional.

6. Relatório datado de 16-10-1937 (ANDRADE, 1981, p. 80).

7. Decreto n. 22.928, de 12-7-1933, erigiu Ouro Preto como Monumento Nacional em razão de a cidade haver sido "teatro de acontecimentos de alto relevo histórico na formação de nossa nacionalidade".
} 
outros conjuntos edificados no período colonial, o da antiga capital mineira comporia a "tradição" da arquitetura moderna brasileira, que então começava a ser reconhecida internacionalmente, o que não seria desdenhado pela política centralizadora e pelo nacionalismo ufanista do período Vargas.

Gradativamente, firmado em concepções nacionalistas que se desenvolviam desde o final do Segundo Reinado, o Sphan moldou as formas de atuação no campo da valorização da cultura brasileira, que se multiplicariam nos órgãos estaduais de tutela do patrimônio criados posteriormente. Em decorrência, embora considerado como representação da nação brasileira, o patrimônio, por longo tempo, se manteria como um conjunto de suportes materiais de símbolos do passado de poucos; nele não se incluíam as manifestações culturais dos segmentos populares, formados por negros, índios e brancos pobres e/ou imigrados, todos tidos como externos à "civilização" de uma nação imaginada como um ente harmônico, isento das disputas inerentes às sociedades e cujas referências históricas se restringiam a alcançar o século XVIII.

\section{TENTATIVAS...}

Em São Paulo, o processo de criação de estruturas públicas relacionadas à tutela de bens culturais transcorreu entre as décadas de 1930 e 1960 e esteve condicionado às possibilidades de seus idealizadores influírem nas decisões de governos. Poucas vezes, como ocorreu em 1962, no segundo Plano de Ação do Governo Carvalho Pinto, a criação de um órgão específico foi prevista como parte das políticas de governo.

Em 1933, a nomeação de Armando de Salles Oliveira, da oposição liberal, para o cargo de interventor em São Paulo possibilitou a instalação do Departamento de Cultura, criado por Paulo Duarte e Mário de Andrade, este também seu primeiro diretor. Valendo-se do art. 180 do Ato 1.146 da Consolidação da Organização Geral da Prefeitura que possibilitava ao diretor do Departamento "traçar, organizar e fazer executar o plano geral do tombamento de defesa do patrimônio artístico e histórico do Município"8, Mário de Andrade pretendia estender a tutela do patrimônio para todo o

8. Carta a Rodrigo Mello Franco de Andrade, 6-4-1937 (ANDRADE, 1981, p. 65). 
estado, caso recebesse o apoio do governo federal. Em carta de 6 de abril de 1937, dirigida a Rodrigo Mello Franco de Andrade, ele expressou essa intenção e a condição para realizá-la: "Resta saber se é possível o Sphan designar o Departamento de Cultura para fazer o serviço geral no Estado e a Prefeitura aceitar a incumbência, o que eu faria aceitar" (ANDRADE, 1981, p. 65).

Não houve designação; manteve-se o caráter nacional das ações de reconhecimento de valores culturais por meio do tombamento. A julgar pela atuação do Departamento de Cultura, essa foi uma oportunidade perdida de inclusão da cultura popular no patrimônio brasileiro, só muito mais tarde alcançada.

No mesmo contexto, entre junho e outubro de 1937, Paulo Duarte promoveu uma campanha visando à criação do Departamento de Patrimônio Histórico e Artístico de São Paulo que, em caso de o candidato da oposição liberal à presidência da República ser vitorioso, se estenderia para o governo federal. Apoiado pelo O Estado de S. Paulo, diário que representava o Partido Democrático, Contra o vandalismo e o extermínio ressaltou o papel ameaçador dos "estrangeiros indiferentes", dos "caboclos broncos" e do descuido dos poderes públicos com a manutenção física do patrimônio histórico. Faltar-lhes-ia amor ao passado, ao mesmo tempo que o cosmopolitismo manifesto em São Paulo impedia o povo de formar uma "consciência nacional" (RODRIGUES, 200o, p. 33-4). Os artigos sugeriam que os bens - grande parte situada em áreas rurais - eram patrimônio dos paulistas cultos, algo dado, herança natural que deveria ser salva, uma vez que ameaçada pelos que eram "incultos" e, muitas vezes, nem sequer brasileiros. Mais uma vez se repetiam antigos argumentos que hoje denominamos xenófobos e se acusava o "cosmopolitismo" como um fator dissolvente do sentimento nacional.

Após um mês do lançamento, a campanha passou a ser coordenada pelo Instituto Histórico e Geográfico de São Paulo e se aproximou ainda mais dos "autênticos paulistas" representados na figura do bandeirante, idealizada e consagrada pela historiografia produzida por membros do próprio instituto, valorizada em 1922 por ocasião das comemorações do Centenário da Independência e, agora, instrumento de propaganda da oposição paulista e de contraponto à criação do Sphan, efetivada em janeiro 
do mesmo ano. Em novembro, as intenções paulistas seriam frustradas como golpe do Estado Novo.

Os esforços para implantação de uma estrutura pública de proteção ao patrimônio paulista seriam retomados no imediato pós-Segunda Guerra Mundial. Então, em decorrência da destruição e da transformação dos valores sociais provocados pelo conflito, tiveram início mudanças fundamentais na perspectiva de proteção a bens culturais, entre as quais a internacionalização do conhecimento a ela relativo. Em torno da Unesco (1945) se constituíram organismos culturais, entre outros, em 1956, o Centro Internacional para o Estudo da Preservação e Restauração de Bens Culturais (ICCROM), organização intergovernamental dedicada ao estudo e à formação de pessoal especializado na conservação do patrimônio cultural e, em 1965, o Conselho Internacional dos Monumentos e Sítios (Icomos), órgão consultor e de colaboração, organizado logo após o II Congresso Internacional de Arquitetos e Técnicos dos Monumentos Históricos (1964) do qual resultara a Carta de Veneza.

$\mathrm{Na}$ década de 1950, Luís Saia, arquiteto que participara de pesquisas e registros da cultura popular desenvolvidos no Departamento de Cultura de São Paulo e, de 1937 a 1975, e dirigiu o $4^{\circ}$ Distrito do então Departamento do Patrimônio Histórico e Artístico Nacional (DPHAN) em São Paulo, visava ampliar o desempenho desse órgão. Para isso, sugeriu um acordo entre os governos federal e estadual de modo a que pudessem atuar em colaboração para preservar monumentos e lugares históricos no estado. Formatada como Projeto de Lei n. 1.472/1950, a sugestão foi apresentada ao legislativo pelo deputado José Alves Cunha Lima e se tornou a Lei n. 1.048, de 5 de junho de 1951, assinada pelo governador Lucas Nogueira Garcez. O art. $3^{\circ}$ previa: "A lei que aprovar o acordo criará o serviço que, em caráter permanente, se dedicará ao trabalho de que trata a presente lei, sempre em colaboração com o órgão federal".

As condições de colaboração foram definidas no documento Sugestões para uma fórmula de colaboração, porém o acordo não se concretizou, uma vez que, segundo Saia (1972, p. 56), a proposta teria desaparecido "misteriosamente nos escaninhos do Palácio e da política”. É possível que o súbito desaparecimento tenha relação com a aproximação do $4^{\circ}$ Centenário da Cidade de São Paulo, cujas comemorações mobilizaram os planejadores 
de obras públicas e altos interesses imobiliários, que puseram a perder referências urbanas na capital. O Sugestões reafirmava a centralização das decisões de proteção no órgão federal; a este caberiam a "orientação na aplicação de verbas" advindas dos cofres estaduais e, também, o controle técnico das intervenções, garantindo, assim, a manutenção de seus critérios de valoração de "documentos da arquitetura brasileira". Quanto às funções do órgão estadual previstas no art. $3^{\circ}$ da Lei n. 1.048, definiram-se apenas as de identificação e classificação de bens. A proteção por meio do tombamento permaneceria exclusiva do governo federal9.

Não foram até o momento localizadas informações detalhadas sobre a atuação de uma comissão nomeada em 1957, pelo então governador Jânio da Silva Quadros (1955-1959). Porém, a nomeação de reconhecidos intelectuais - Sérgio Buarque de Holanda, Lourival Gomes Machado e Ernani Silva Bruno - para elaborar um anteprojeto do Serviço de Patrimônio Histórico e Artístico do Estado de São Paulo indica que havia disposição política para tanto. Ao que consta, por desentendimentos entre o político e dirigentes da Universidade de São Paulo, o novo Serviço não seria criado (RODRIGUES, 2000, p. 36-40). O governador optou, então, por atuar no campo da "cultura histórica" por meio da educação; para tanto, em diversas cidades do estado, criou museus histórico-pedagógicos que, até 1968, foram vinculados à Secretaria de Educação. Por meio deles, pretender-se-ia manter "permanente culto das tradições nacionais" e formar uma vigilante consciência cívica, afirmava a mensagem enviada por Jânio Quadros à Assembleia Legislativa, em 13 de março de 1959.

O responsável pela expansão da rede de museus, por meio da qual se pretendia também preservar a história das cidades paulistas e a memória do patrono de cada unidade museal, foi Vinício Stein Campos que, depois, esteve diretamente envolvido na criação do Condephaat e integrou seu colegiado desde a criação até 1975. Assim, por diferentes vetores, a construção da memória por meio do patrimônio, fator essencial para o desenvolvimento da relação da sociedade com seu passado, continuaria a ser feita por setores conservadores, a ser pontuada de fatos e personagens heroicos e sob o ponto de vista da exclusão. 


\section{PARA SALVAR O PATRIMÔNIO PAULISTA...}

Os pouco mais de 30 anos transcorridos entre a criação do Sphan, em 1937, e o Condephaat, no ano 1968, foram de solidificação da prática brasileira de proteção ao patrimônio como representação da nação e da tradição da moderna arquitetura brasileira. Internacionalmente, porém, continuavam experiências de preservação essenciais para a adequação do patrimônio às demandas da sociedade contemporânea, o que, também, daria ensejo a conceitos que apontavam para a aliança da tutela de bens culturais a políticas públicas de promoção de melhor qualidade de vida.

O caso de preservação de áreas históricas na cidade de Bolonha, iniciado em 1964, é um importante marco desse período, pois mostrou a potencialidade da manutenção física de "heranças do passado", de suportes de memórias, quando contam com o apoio de seus protagonistas e atendem a melhorias locais. Também se privilegiaram aí a percepção do passado como constituinte do cotidiano pessoal e coletivo e o potencial de seu valor de uso como fator de integração à dinâmica econômica.

A possibilidade de criação de um órgão voltado à tutela pública de bens de valor histórico no estado de São Paulo surgiu no período de centralização política e autoritarismo instalado em 1964 e se realizou sob condições bastante particulares, a começar pelos aspectos legislativos. Desse ponto de vista, seria apropriado criá-lo diretamente por uma lei ordinária, mas, por injunções políticas, ele o foi por meio de uma emenda à Constituição de 1967, apresentada ao plenário pela deputada Dulce Sales Cunha Braga ${ }^{10}$. A emenda se tornou o art. 128 da nova constituição: "É criado o Conselho de Defesa do Patrimônio Histórico, Artístico e Turístico do Estado, na forma que a lei estabelecer".

Os procedimentos para a criação do Condephaat diferiram bastante dos adotados em outros casos durante a gestão Abreu Sodré. Em 1967, ele instalou o Grupo Executivo da Reforma Administrativa (Gera), que

10. Dulce Sales Cunha Braga foi escritora e educadora e liderou programas de rádio e TV. Filiada à União Democrática Nacional (UDN), elegeu-se vereadora por dois mandatos. Em 1964, esteve entre os articuladores da Marcha da Família com Deus pela Liberdade, que precedeu o movimento de deposição do presidente João Goulart. Com a instalação do bipartidarismo, ingressou na Aliança Renovadora Nacional (Arena), partido da situação, e, em 1966, elegeu-se deputada estadual. Disponível em: http://www.fgv.br/cpdoc/ acervo/dicionarios/verbete-biografico/braga-dulce-sales-cunha. Acesso em: 11 jul. 2018. 
centralizava e controlava a execução de medidas que objetivavam renovar a administração pública em São Paulo. Por seu crivo passaram os projetos de criação da Fundação Padre Anchieta, dos museus de Arte Sacra, da Casa Brasileira e da Imagem e do Som; e de eventos culturais como o Festival de Campos do Jordão. Também coube ao Gera a estruturação da Secretaria de Cultura, Esporte e Turismo que locaria, entre outras instituições, o Arquivo do Estado, a Pinacoteca, o Conselho Estadual de Cultura, a Divisão de Museus Históricos e Pedagógicos e o próprio Condephaat.

Luís Dória, um dos membros do Gera, afirmou que não havia então um programa de governo articulado antecipadamente, o que daria espaço à concretização de propostas de diferentes setores da sociedade, dependendo de seu acesso aos canais de decisão ${ }^{11}$. A também integrante do Gera, Waldisa Russio Camargo Guarnieri, criadora e docente do primeiro curso de Museologia em São Paulo, observou que as diversas iniciativas culturais do Grupo não faziam parte de uma política de governo; porém, no seu entender, eram "projetos de uma vanguarda política e intelectual que pode operar aproveitando contradições do governo autoritário e traduzindo, à sua maneira, a obrigação constitucional de o Estado amparar a cultura"12. Essa vanguarda, ao contrário do que ocorrera na década de 1930, não incluiu em seus projetos a criação de um órgão público de proteção ao patrimônio; restringiu suas escolhas ao planejamento e instalação de estruturas adequadas ao desenvolvimento de políticas estaduais de guarda, produção e difusão cultural capazes de responder ao que gradativa, mas rapidamente, vinha se acentuando em nossa sociedade, o consumo de bens culturais. É provável que a perspectiva turística tenha influenciado positivamente na criação do Condephaat, uma vez que ia ao encontro de recomendações da Unesco de aproveitamento econômico das potencialidades naturais e culturais ${ }^{13}, \mathrm{o}$

11. Entrevista, 21-2-1991. Citado em Rodrigues (2000, p. 42).

12. Entrevista concedida a Maria Lúcia Pinheiro Ramalho e Walter Pires, em 28-4-1984 (RODRIGUES, 200o, p. 43).

13. Segundo Leal (2008), em 1964, o Iphan recebeu a primeira “missão” da Unesco; então Paul Coremans visitou quatro cidades brasileiras com potencial turístico. Entre esse ano e o de 1979, outras missões, como a de Michel Parent, vieram ao país, visitaram cidades de interesse turístico e recomendaram ao Iphan a adequação de procedimentos técnicos de modo a possibilitar seu aproveitamento. Em 1967, a Organização dos Estados Americanos (OEA) promoveu uma reunião que resultou no documento Normas de Quito, do qual o Brasil foi signatário; aí o turismo foi abordado como forma de obtenção de recursos e de criação de atividades econômicas, geradoras de empregos. No período, o governo federal criou a estrutura administrativa necessária ao desenvolvimento da 
que, norteado pela ideia de consumo cultural, projetava resultados sociais bastante diversos daquele experimentado no mesmo período em Bolonha.

A Lei n. 10.247, de 22 de outubro de 1968, que dispôs sobre a competência, organização e o funcionamento do Condephaat, resultou de definições de uma comissão especialmente constituída pelo governador Roberto de Abreu Sodré (1966-1971) ${ }^{14}$, junto à Secretaria de Governo, e foi composta por pessoas de diferentes formações: Olavo Fernandes, procurador do Estado; Francisco Ruiz Ribeiro, jornalista; Miroel Silveira, advogado, escritor, professor e teatrólogo, então assessor cultural da Secretaria de Governo; Eurípides Simões de Paula, advogado, historiador, professor e duas vezes vice-reitor da Universidade de São Paulo; Vinício Stein Campos, pedagogo, diretor da Divisão de Museus Históricos e Pedagógicos e membro do Instituto Histórico e Geográfico de São Paulo; e Lúcia Piza Figueira de Mello Falkenberg, presidente do Instituto Histórico Geográfico de GuarujáBertioga, cuja atuação fora essencial à necessária articulação política que propiciou a criação do órgão havia muito tentada. A estrutura adotada para o novo Conselho seguiu o modelo administrativo e legal do Iphan, definido no Decreto n. 25. Também se mantiveram idênticas as funções, os conceitos operacionais e os procedimentos técnicos de trabalho. Não foi então considerada necessária a adequação do modo de preservar ao novo contexto social expresso no acelerado processo de urbanização do estado de São Paulo e de metropolização de sua capital, no qual eram contínuas a chegada de migrantes de diferentes partes do país e a diversificação cultural da população.

Os contatos entre o conjunto da sociedade e o Condephaat ficaram restritos à possibilidade de esta solicitar a abertura de processos de estudo de tombamento. Do colegiado, ao qual cabiam todas as decisões de proteção e preservação, não participaram associações civis que de alguma forma

atividade (Decreto-Lei n. 55/1996 cria a EMBRATUR e o Conselho Nacional de Turismo). E, no campo da preservação, em 1972, teve início o Programa de Cidades Históricas (PCH), então sob responsabilidade direta da Secretaria de Planejamento da Presidência da República.

14. Roberto Costa de Abreu Sodré, advogado e político, foi um dos fundadores da União Democrática Nacional (UDN) e, no decorrer da década de 1950, exerceu três mandatos de deputado estadual por essa legenda que também presidiu. Em 1966, ingressou na Arena; no ano seguinte, assumiu o governo de São Paulo, aí permanecendo até 1971. Disponível em: http://www.fgv.br/ cpdoc/acervo/dicionarios/verbete-biografico/roberto-costa-de-abreu-sodre. Acesso em: 11 jul. 2018. 
refletiam a complexidade da vida urbana, mas apenas instituições onde se concentravam pessoas cultas: universidades, Igreja, instituto dos arquitetos e, naturalmente, institutos históricos, além de secretarias de governo, representação esta que aumentaria sensivelmente com o decorrer dos anos. Mais uma vez, a proteção a bens culturais não estava no horizonte dos projetos do governo, o que abriu espaço para atuação de um grupo conservador e tradicionalista que mantinha vínculos com institutos históricos e se valeu de suas redes de influência e da obrigação do Estado de apoiar a cultura, criando um órgão que manteve a exclusão social e a valorização da cultura erudita e das elites. Em 1969, foram tombados solares, palácios e palacetes de figuras de destaque na sociedade rural e uma edificação de apoio às atividades de defesa militar do território, correspondentes ao século XIX; dois núcleos históricos do período colonial, e o conjunto de obras de Benedito Calixto ${ }^{15}$, todos portadores de inegável valor cultural. Os critérios que nortearam os tombamentos no primeiro ano de atuação do Condephaat expressaram valores históricos, artísticos e éticos que justificavam a desigualdade então crescente na sociedade brasileira.

\section{LIMITES}

Não seria exagero afirmar que, no âmbito administrativo, o Condephaat é um órgão que vem enfrentando oscilações de prestígio e inúmeras dificuldades à sua atuação. Nesse quadro limitador, também foram oscilantes os esforços para romper antigos critérios de atribuição de valor cultural aos artefatos analisados, ou seja, critérios de seleção de bens a serem tutelados pelo poder público. Desde a década de 1970, quando a distinção "patrimônio da humanidade" foi constituída e se verificou uma sensível ampliação das categorias de patrimônio e de conceitos que nos chegavam sistematizados em forma de cartas e recomendações, é possível localizar iniciativas isoladas que buscavam aplicá-los à prática do Condephaat. Talvez possamos denominar esses esforços de "ensaios individuais para a definição de políticas

15. Livros do Tombo. Cedoc Condephaat. No Livro de Tombo Histórico foram inscritos: Solar do Major Novaes, em Cruzeiro; Palacete Palmeira e Palácio 10 de julho, em Pindamonhangaba; Centro Histórico de Cananeia; e Centro Histórico de São Sebastião. No Livro do Tombo Arqueológico, Etnográfico e Paisagístico: Palácio do Imperador, em Itapura. Livro do Tombo das Artes: Obras do Pintor Benedito Calixto de Jesus. 
governamentais", que acabariam por não se concretizar. Possivelmente, como observa Kühl (2010), o caráter apenas indicativo desses documentos ainda não foi bem entendido entre nós, o que possivelmente tenha dificultado torná-los referências para a efetiva renovação de metodologias, de modo a atender a diversidade das solicitações de estudo de tombamento. Tais "ensaios" deixaram rastros potencialmente capazes de mudar perspectivas de atuação e esmaeceram a concepção de "defesa" do patrimônio como "missão de pessoas cultas" construída mesmo antes da formação do órgão federal.

Ainda que, como observa o antropólogo e presidente do Condephaat entre 1989 e 1991, Edgard de Assis Carvalho (2005, p. 139), seja imperativo refundar a "noção de patrimônio histórico, cultural [...] como um patrimônio bio-histórico-cultural", o que inauguraria a sua "fase civilizatória", houve períodos em que certa renovação foi favorecida por contextos políticos - entre eles, o de "abertura" -, ou se deu em decorrência do conceito de patrimônio relacionado à formação profissional de alguns presidentes do Conselho.

No período Franco Montoro (1983-1987), primeiro governador eleito pelo voto direto após 1964, alimentaram-se as esperanças de dinamização das atividades do Condephaat e de sua atuação em favor da qualidade da vida urbana; data de então o tombamento do bairro Jardins, em São Paulo (1985). Foi também nesse período que, por iniciativa de alguns técnicos, começou a se desenvolver o projeto "Memória Escolar", que buscou valorizar memórias locais e políticas públicas de educação, por meio do tombamento de escolas construídas na Primeira República, quando a instrução era tida como um fator de progresso nacional.

Pela primeira vez, o colegiado seria presidido sucessivamente por um geógrafo, Aziz Ab’Saber (nov.1982/mar.1983) e por um antropólogo, Antonio Augusto Arantes (1983-1984), que imprimiram às suas gestões diretrizes promissoras. Com visões distintas, ambos promoveram sensível ampliação dos limites de atuação e souberam capitalizar a potencialidade técnica de seus profissionais. Ab'Saber iniciara sua participação no Condephaat em 1976, como conselheiro. Crispim (2016, p. 140-6) observa que a ele se deve a mobilização do tema "patrimônio paisagístico", desde o início dos anos 1970 discutido no colegiado, para a construção de uma política de proteção 
às "áreas naturais". Os valores então não estavam relacionados ao meio ambiente, mas à tradição e ao consumo cultural, como explicita Lúcia Falkenberg, por ocasião do primeiro tombamento classificado como "áreas naturais e paisagens", o Bosque dos Jequitibás, em Campinas ${ }^{16}$.

O objetivo do Conselho é dar oportunidade à cidade de Campinas de preservar e captar o clima antigo do nosso passado, clima este que já está trazendo à cidade um grande fluxo de turistas e interessados em antiguidades [...] (apud GALVEZ, 2008, p. 38.)

A perspectiva da preservação da natureza como um bem relevante para a qualidade de vida e passível de ser protegida pelo tombamento foi construída no Condephaat por Ab'Saber e, além do tombamento de outras áreas de importância ecológica, em 1985, resultou no da Serra do Mar (CRISPIM, 2016, p. 140). Essa medida polêmica foi analisada por Simone Scifoni (2006), geógrafa que fez parte da equipe de profissionais organizada pelo professor, posteriormente dissolvida em razão de injunções políticas. A respeito da “equipe de áreas naturais", em entrevista publicada em 2008, Carvalho observou tratar-se de:

[...] um conjunto de quatro funcionários, biólogos de formação, emprestados da Companhia de Eletricidade do Estado de São Paulo (Cesp) para opinar sobre as ditas questões ligadas à natureza. Essa equipe foi uma inovação e teve duas funções: mostrar para o Conselho que a natureza e a cultura estavam articuladas e evidenciar que os biólogos, por vezes, tinham uma visão mais ampla do que a de historiadores, arquitetos, sociólogos e antropólogos [... $]^{17}$.

Arantes escolheria como meta principal de sua gestão promover a aproximação entre o Condephaat e a sociedade. O distanciamento existente, e até hoje não superado, foi considerado um dos fatores da crítica situação de conservação da maior parte das unidades, conjuntos arquitetônicos e

16. Processo Condephaat n.09907/69, tombamento no ano seguinte. 17. Entrevista realizada e citada por Galvez (2008, p. 103). 
núcleos urbanos sob proteção do governo paulista. Para localizar possíveis razões, ele promoveu uma pesquisa de recorte antropológico na cidade de Santana do Parnaíba, cujo centro histórico fora tombado em 1982 produzindo uma forte resistência às restrições impostas pelo ato, quanto a intervenções nas edificações. Os resultados levariam ao desenvolvimento, entre os técnicos, de uma percepção das agressões ao patrimônio, diferenciada daquela apontada desde a década de 1930, quando atribuída à ignorância dos "incultos". O resultado mostrou que a reação local derivava da forma excludente de seleção dos bens pelos "de fora", o que, de acordo com os "de dentro", não havia contemplado aqueles por eles considerados mais representativos. Tratava-se não apenas da participação, mas, sobretudo, de critérios de valoração cultural. A pesquisa pouco depois se tornou um trabalho acadêmico que mostrou a importância da produção do conhecimento sobre os órgãos de preservação e do constante diálogo desses com a Universidade ${ }^{18}$.

Outra publicação, Produzindo o passado (ARANTES, 1994), cujo título denota o entendimento da memória como uma construção social realizada no presente, afirmaria a importância desse diálogo e a preocupação em renovar as formas de pensar a preservação. Ela resultou de um seminário organizado na gestão Arantes, em 1983, oportunidade em que foi possível desenvolver reflexões teóricas sobre temas diretamente relacionados a prática do órgão, cultura, história, poder e, especialmente, memória, além de outros relativos a aspectos técnicos.

Em 1990, durante o período do antropólogo Edgar de Assis Carvalho na presidência do Conselho, pela primeira vez um bem de matriz africana teve seu valor cultural reconhecido pelo tombamento. Esse foi decidido após uma tramitação bastante conturbada de um processo iniciado em 1988. Obstáculos travestidos de questões técnicas e, no Conselho, discussões infindáveis sobre o caráter do bem - imaterial, posto que fosse manifestação religiosa, não cabendo assim o tombamento, pois este exigiria materialidade, ou material e, nesse caso, o bem não apresentava atributos arquitetônicos que justificassem o tombamento - prolongaram a decisão até 1990, quando 
estratégias adotadas pela presidência do Conselho mostraram sua eficácia diante do fato inédito no órgão, o tombamento de um terreiro de candomblé.

A convite de Carvalho, mãe Silvia de Oxalá, "com suas roupas e adereços de babalorixá, acompanhada por suas filhas de santo", compareceu a uma reunião do Conselho e surpreendeu os conselheiros com sua postura serena de autoridade religiosa reconhecida. Naquele momento, diz Carvalho em uma entrevista, a "religação do material e do imaterial foi explicitada" Era o que ele, a partir de argumentos, tentara fazer por meses...

Carvalho valeu-se também de um estudo solicitado a um grupo de professores universitários especializados em religião, sobre a importância cultural das manifestações religiosas de matriz africana em nosso país e, especificamente, do Axé Ilê Obá. À conclusão desse grupo somaram-se argumentos apresentados na informação técnica do processo resultando na aprovação do tombamento, o que representou o reconhecimento da legitimidade de um sistema de valores específicos, que, a despeito de frequentes discriminações, integra a cultural paulista.

\section{PASSADOS 50 ANOS...}

Os casos aqui abordados, selecionados entre muitos outros, apenas exemplificam os esforços que foram realizados para diversificar a representação social do patrimônio. As dinâmicas da sociedade e das disciplinas relacionadas ao patrimônio exigem, porém, a constante adequação do corpo de conceitos operacionais sobre o qual se constroem as metodologias necessárias à afirmação da sociedade como foco das ações de preservação. Isso exige romper os limites de antigas práticas de análise dos bens, por vezes definidas individualmente, e se considerem valores e finalidades de outras áreas de atuação pública, como a do planejamento urbano e meio ambiente, sem descuidar do patrimônio como vetor de memória de grande potencialidade em razão de estar, em grande parte, exposto à fruição pública e compor paisagens de identificação entre indivíduos e os lugares em que atuam. Nem sempre as razões que justificam a proteção do poder público são oferecidas pela arquitetura, pela memória ou pela história. Embora não caibam aqui amplas considerações teóricas sobre a História, vale observar

19. Entrevista realizada e citada por Galvez (2008, p. 107) 
que, nesse campo, hoje se discute não só o que é fato, mas o que é história, ambos os pontos bastante controversos. Para alguns, fatos históricos são aqueles que têm consequências e possibilitam mudanças, enquanto para outros, eles não existem em si, mas são eleitos como tais. Assim como em relação à antiga definição legal de patrimônio cabia perguntar "o que são fatos memoráveis da História do Brasil?", hoje cabe questionar qual a História que orienta a atribuição de valor histórico a um artefato. Essa, assim como o patrimônio, é uma construção social, tem historicidade, reflete o tempo de sua criação. Tampouco é a "verdade" sobre o passado e, por isso, se torna necessário indagar de que ponto de vista ela foi construída e sobre quem ela informa. E quem ela esquece?

Referindo-se a Paul Veyne, Meneses lembra que "histórico é exatamente aquilo que fica no espaço intermediário entre o que é universal e o que é singular"; entre a "homogeneidade absoluta" e a "heterogeneidade irredutível”. E continua: "é através da diferença que existe história. É a dialética da diferença, e dialética implica, justamente, o movimento. [...] Em última análise, é aquilo que é capaz de acarretar mudança. A mudança é que é a substância da história" (MENESES, s. d., p. 6).

Conclui-se que histórico é o que provoca a mudança a partir da diferença e do movimento. Esta parece não ser a definição utilizada na maioria dos estudos de tombamento, uma vez que, com muita frequência, eles são classificados como representação de um tempo cronologicamente fixado, artificialmente estático, desprovido do antes e depois, o que subtrai do bem a representação do contínuo processo social de mudança social; em suma, subtrai-lhe a historicidade.

É também comum atribuir-se aos objetos em estudo de tombamento a qualidade de documentos. Mais uma vez recorro a Meneses, que afirma: "nem todas as coisas passíveis de carrear informações são documentos", são apenas "suportes de informação relevante", mostram "mecanismos por intermédio dos quais uma sociedade se organiza a si própria, age e, sobretudo, se transforma" e, como "o homem continuamente cria e recria sua realidade”. Qualquer objeto, conclui ele, é "repositório de uma informação sobre relações entre os homens", uma espécie de "resíduo físico das relações sociais" entre as quais o autor realça o trabalho, uma vez esse "constrói a realidade e a história" (MENESES, s. d., p. 6-7 e 13). 
O trabalho a que se refere o autor é aquele inscrito nos objetos construídos no passado a eles imprimindo "valor histórico" não apenas devido ao tempo transcorrido, mas, sobretudo, porque representam o dispêndio e o resultado da capacidade do homem criar; e porque, no presente, sob diversas formas, podemos ainda nos beneficiar desses esforços dos que viveram antes de nós. O trabalho é, portanto, um forte impulsionador da memória por meio da qual é possível estabelecer laços de continuidade e carregar as ações cotidianas de experiências que mesmo não vividas por nós, passam a integrar nossas vidas e sustentam a construção das relações entre a sociedade e seu passado.

\section{SÃO OUTROS TEMPOS...}

É indiscutível que após 50 anos de atuação os resultados sociais da ação do Condephaat são positivos. Parece-nos, porém, que o momento é de renovação, o que implica mudanças profundas que garantam sua historicidade e adequação às expectativas da sociedade a partir da Constituição de 1988.

Nesta, a definição de patrimônio - conjunto de bens "portadores de referência à identidade, à ação, à memória dos diferentes grupos da sociedade brasileira [...] ${ }^{20}$ - abriu um importante espaço para que os grupos antes silenciados reivindicassem o reconhecimento de suas culturas. Mais que pela História, isso vem sendo obtido pela memória, caminho que mobiliza afetos e tem poder transformador. Não a memória banalizada como produto de consumo, mas a que reafirma experiências vividas por segmentos sociais como fatores desencadeadores de pertença; memória que sustenta a força individual e coletiva de reivindicação do direito ao passado e ao redesenho de lugares sociais.

$\mathrm{O}$ art. 125 da mesma Carta de 1988 garantiu "o pleno exercício dos direitos culturais", concebidos como aqueles que dizem respeito "às artes, à memória coletiva e ao repasse de saberes, que asseguram a seus titulares o conhecimento e uso do passado [...] visando a dignidade da pessoa humana" (CUNHA FILHO, 200o, p. 34). É como direito que a sociedade vem retraçando a abrangência política do patrimônio cultural e da memória; 
hoje eles não são mais naturalizados, e sim percebidos como construções sociais contínuas, mas mutáveis, porque têm historicidade, e passíveis de defesa legal ${ }^{21}$.

Nos últimos anos, movimentos independentes, organizados por setores jovens da população, vêm trabalhando na defesa das memórias locais - e, diga-se, não apenas as representadas na cultura material -, valorizadas a partir de critérios particulares definidos como essenciais ao desenvolvimento da pertença e ao exercício da urbanidade. A região Leste de São Paulo, uma das mais populosas da cidade, espelha claramente essa concepção independente do exercício do direito à memória, na qual o papel do poder público vem sendo recolocado como complementar às definições dos sujeitos sociais sobre o que representam suas memórias. Essa postura revela insatisfação, ao menos parcial, com os resultados da ação pública de reconhecimento de bens culturais, e aponta o anacronismo dos parâmetros oficiais de instituição do patrimônio e a concepção de cultura que as orienta: ter cultura não é uma distinção, mas algo comum a todos os indivíduos e grupos sociais.

Queremos acreditar que o processo de rompimento da perspectiva tradicionalista de proteção ao patrimônio cultural vem se fortalecendo, o que é promissor para que este exerça um papel de destaque na melhoria da qualidade de vida, uma entre as inúmeras potencialidades da memória.

\section{REFERÊNCIAS}

ANDRADE, Mário. Anteprojeto, Serviço de Patrimônio Artístico Nacional. MEC. SPHAN próMemória, p. 90-106, 1980.

ANDRADE, Mário. Cartas de trabalho. Correspondência com Rodrigo Mello Franco de Andrade (1936-1945). Brasília, D.F.: Secretaria do Patrimônio Histórico e Artístico Nacional/ Fundação Pró-Memória, 1981.

ARANTES, Antonio Augusto (Org.). Produzindo o passado: estratégias de construção do patrimônio cultural. São Paulo: Brasiliense, 1984.

AZEVEDO, Carmem Lúcia de. Jeca Tatu, Macunaíma, a preguiça e a brasilidade. Tese (Doutorado em História) - Faculdade de Filosofia, Letras e Ciências Humanas, Universidade de São Paulo. São Paulo, 2012.

21. O art. 129 da Constituição de 1988 especifica as funções do Ministério Público, instituição que tem autonomia em relação à estrutura do Estado, cabendo-lhe também questionar a atuação dos órgãos públicos. Sua atuação em defesa do cidadão está baseada nos direitos difusos e coletivos, entre os quais se situam questões relativas ao meio ambiente e aos bens culturais. 
CARVALHO, Edgard de Assis. Entrevista concedida a Alexandre Fernandes Corrêa, em 18.3.1999. Caderno Pós Ciências Sociais, São Luís, v.2, n.3, p. 125-40, jan./jun. 2005.

CRISPIM, Felipe Bueno. Entre a geografia e o patrimônio: estudo das ações de preservação das paisagens paulistas pelo Condephaat (1969-1989). São Bernardo do Campo: EdUFABC, 2016.

CUNHA FILHO, Francisco Humberto. Direitos culturais como direitos fundamentais no ordenamento jurídico brasileiro. Brasília, D.F.: Brasília Jurídica, 2000.

GALVEZ, Beatriz Lourenço Peixoto. Cultura e patrimônio. Tese (Doutorado em Ciências Sociais) - Pontifícia Universidade Católica. São Paulo, 2008.

HOBSBAWM, Éric J. Nações e nacionalismo desde 1780. Programa, mito e realidade. Rio de Janeiro: Paz e Terra, 1990.

KÜHL, Beatriz Mugayar. Notas sobre a Carta de Veneza. Anais do Museu Paulista, São Paulo, v.18. n. 2, p. 287-320. jul./dez. 2010.

LEAL, Cláudia F. Baeta. As missões da Unesco no Brasil: Michel Parent. Rio de Janeiro: Iphan, Copedoc, 2008.

MENESES, Ulpiano Bezerra de. O objeto material como documento. Moodle USP: e-disciplinas, [S. I.]. Disponível em: https://edisciplinas.usp.br/pluginfile.php/3959717/mod_resource/ content/1/BEZERRA. Acesso em: 23 jul. 2018.

MENESES, Ulpiano Bezerra de. Os museus e as ambiguidades da memória: a memória traumática. In: $10^{\circ}$. ENCONTRO PAULISTA DE MUSEUS, São Paulo, 18 jul. 2018. Disponível em: https://www.sisemsp.org.br/wp-content/uploads/2018/o8/Ulpiano-Bezerra-de-Meneses. pdf. Acesso em: 3 dez. 2018.

PERES, Fernando da Rocha. Memória da Sé. Salvador: Edições Macunaíma, 1974.

PINHO, Wanderley. Proteção dos monumentos públicos e objetos históricos. Revista do Instituto Geográfico e Histórico da Bahia, v. 43, p. 191-198, 1918.

RODRIGUES, Marly. Imagens do passado: a instituição do patrimônio em São Paulo: 1969-1987. São Paulo: Editora Unesp; Imprensa Oficial do Estado; Condephaat; Fapesp, 2000.

RODRIGUES, Marly. O Brasil na década de 1910: a fábrica e a rua, dois palcos de luta. São Paulo: Ática, 1997.

SAIA, Luís. Morada paulista. São Paulo: Perspectiva, 1972.

SANTOS, Fábio Lopes e Souza. Almeida Júnior, modernização e identidade paulista: pintura da vida moderna, o Caipira e os Bandeirantes. In: XXIV COLÓQUIO DO CBHA, 2004, Belo Horizonte. Anais [...]. Belo Horizonte: CBHA, 2004. Disponível em: http://www.cbha.art.br/ coloquios/2004/anais/textos/31_fabio_lopes_souza_santos.pdf. Acesso em: 18 ago. 2018.

SCIFONI, Simone. A construção do patrimônio natural. Tese (Doutorado em Geografia) Faculdade de Filosofia, Letras e Ciências Humanas, Universidade de São Paulo. São Paulo, 2006. 